\title{
Teoria crítica e indústria cultural
}

\section{Rodrigo Duarte}

Belo Horizonte: Editora UFMG, 2003.

Adorno continua sendo um dos maiores pensadores da arte na modernidade e da crítica da cultura de massa. O que geralmente ocorre hoje é que, embora, de maneira inevitável, ele seja reconhecido, de um lado, dáse importância exagerada aos seus diagnósticos falhos (por exemplo, sobre o jazz e Stravinski) e, de outro, minimiza-se ou desconhece-se a riqueza ainda pouco explorada de suas reflexões sobre a cultura no século XX. O livro Teoria crítica e indústria cultural, de Rodrigo Duarte, oferece uma contribuição essencial para corrigir um pouco esse problema, ao estudar um dos conceitos mais profícuos de Adorno e Horkheimer: a indústria cultural.

No primeiro capítulo, há um esboço dos primórdios da escola de Frankfurt que mostra qual o contexto em que Adorno se exilou da Alemanha e emigrou para os Estados Unidos (:13-9), para então abordar textos que reúnem os pressupostos teóricos da crítica à indústria cultural. No texto "Sobre o caráter afirmativo da cultura" (: 19-21), Marcuse afirma que, embora o capitalismo tenha acentuado as diferenças de classe, a cultura seria uma prática social que carrega o potencial de uma relação igualitária entre os homens. Na Idade Moderna, no entanto, Marcuse percebe argutamente que a arte burguesa promove a manutenção ideológica da desigualdade. Faltava a ele uma diferenciação mais precisa entre a cultura tradicional e sua versão industrializada. Tal salto foi alcançado por Benjamin no famoso ensaio "A obra de arte na era de sua reprodutibilidade técnica".

No texto "O fetichismo na música e a regressão da audição", Rodrigo Duarte encontra em Adorno, o principal autor do conceito de indústria cultural, traços conceituais prévios do que seria posteriormente concebido de forma mais determinada. Para Adorno, há certa indiferenciação entre a música erudita e a de entretenimento quando ambas são transformadas em mercadoria. Em termos estruturais, todavia, na música de massa as partes não têm relação com o todo da composição, o que diminui o valor e a necessidade de uma atenção específica do ouvinte. Nesse caso, a configuração objetiva do bem cultural influi perigosamente na experiência subjetiva e, à medida que essa reciprocidade se torna um hábito, configura-se uma estrutura de consumo empobrecedora da experiência (: 30-3). 
Há uma suposta ausência do valor de uso na mercadoria cultural que se transforma, ela própria, em valor de uso. Se na mercadoria utilitária já ocorre o que Marx analisou como o caráter de fetiche, que esconde as relações sociais como exploração do trabalho alheio pelo capital, a mercadoria cultural, ao fazer da inutilidade um emblema, reforça sob a aparência de imediaticidade o caráter de valor de troca e a onipresença do mercado em sua essência (: $33 ; 67)$.

No capítulo II, em que há uma exposição do livro Dialética do Esclarecimento, Rodrigo Duarte destrincha as relações entre o mito e o Esclarecimento, mostrando como a própria mitologia pôs em movimento o processo do Esclarecimento, como há uma conaturalidade entre os dois termos e o quanto os traços da proposição científica, que depende de um princípio de repetição do experimento, podem ser encontrados no mito, que iguala tudo com tudo.

Quando a ciência começa a tomar o espaço da religião, Adorno observa que o mundo burguês limita o saber, mas isso não ocorreu para obter espaço para a arte, e sim para a fé. Contudo, e a despeito da sensibilidade à crise de valores instaurada, a religião não se conservou em si mesma. Mesmo assim, a racionalidade científica se tornou um força cega da natureza, um novo instrumento do mito, contra a ligação do esclarecimento emancipador ligado à arte. A partir desse ponto, a exposição do livro e das idéias de Adorno se torna muito condensada e precisa. Escolheremos apenas alguns momentos.

No esquematismo dos conceitos puros do entendimento de Kant em Crítica da razão pura, há uma análise de como o sujeito organiza a apreensão da multiplicidade sensível no sentido interno (tempo) a partir de esquemas que medeiam a relação do conceito puro com a sensibilidade. No capítulo de Dialética do esclarecimento que expõe o conceito de indústria cultural, "Indústria cultural: o Esclarecimento como mistificação das massas", os autores afirmam que a própria indústria toma o trabalho das faculdades do sujeito com um planejamento antecipado, uma classificação prévia dos dados apresentados. Dessa forma, esse trabalho poupado impõe o esquematismo da produção e contribui para a passividade e a estagnação do sujeito no nível das faculdades. Aqui percebemos que Adorno elaborou filosoficamente ainda mais aquilo que estava concebido no texto sobre a música (54-55). A arte de vanguarda, por oposição, procurou, de sua parte, aumentar a dificuldade da recepção e problematizar sua organização prévia e estereotipada.

Como esse procedimento se reproduz dentro do sistema, chega-se a um ponto em que todos aqueles que trabalham na indústria cultural não saberiam fazer de outra forma, como se esse modo de trabalhar fosse 
"natural" e não historicamente datado, sem que eles se dêem conta de que, mesmo participando da produção, estão reproduzindo os modos de feitura anteriores (:62). Os consumidores, por sua vez, não aceitarão uma mercadoria diferente, e a proposta do sistema é de que a humanidade inteira se torne cliente ou empregado da indústria. A coragem de se posicionar contrariamente a esse círculo, introduzida pela modernidade trágica principalmente da literatura e da música românticas, elevadas no modernismo, agora se tornou extinta. A cultura de massa absorve o trágico no drama calculado.

Em seguida, Rodrigo aborda o capítulo sobre o anti-semitismo atento para as relações com o capítulo anterior (69-75). O capítulo III oferece uma análise das inserções do conceito de indústria cultural nas abordagens sociológicas de Adorno. Rodrigo trabalha a relação do livro Dialética do Esclarecimento com os estudos intitulados $A$ personalidade autoritária, que tiveram a participação de Adorno. Em seguida, mostra que a crença na astrologia, explorada por uma coluna diária do Los Angeles Times, foi estudada por Adorno entre 1952 e 1953. Essas crenças são perigosas porque carregam elementos pseudo-racionais vendidos ideologicamente como racionais (: 86). Ajudam o indivíduo em seu esforço de adaptação para a sobrevivência, sem questionar o status quo; ao contrário, induzem a que se permaneça satisfeito com as injustiças e cegueiras da ordem vigente. $\mathrm{O}$ fato de haver, na sociedade da comunicação e informação, mais acesso à cultura que em épocas predecentes é neutralizado pelo trabalho da cultura de massa em diminuir a capacidade de processar as informações relevantes de forma adequada. A astrologia, com seu mundo imaginário de fantasias do destino pessoal, outros oráculos orientais, livros de auto-ajuda, misticismos reflexivamente pobres e ilusórios, todos instrumentos infelizes para suportar o desespero do mundo trágico objetivo e subjetivo, todo esse arsenal de dopantes pseudo-racionais, enfim, não levam o indivíduo sequer a suspeitar da complexidade das relações de dominação e dos processos de regressão de que é vítima.

Adorno aborda no texto "Teoria da semicultura" a crise da formação cultural, ligada naturalmente à crise da cultura, e afirma que toda formação cultural que não aponte esses procedimentos de neutralização da cultura, de anulação da potencialidade da cultura para a maioridade e autonomia crítica do indivíduo, torna-se semi-erudição, semicultura (:93). A semicultura, portanto, não é falta de cultura; é nada mais, nada menos que um planejamento de anulação das possibilidades libertadoras tanto da cultura quanto da ignorância curiosa e desconfiada (: 96). A semicultura não é um estado intermediário para alcançar a cultura; é, na verdade, sua maior inimiga. 
A relação entre estética e indústria cultural é o tema do quarto capítulo, que trata dos livros Minima moralia, Filosofia da nova música e Teoria estética. No segundo livro, Rodrigo percebe que Adorno produz uma rica dialética da relação entre a cultura de massa e a música radical erudita do século XX, atonal ou dodecafônica, que talvez seja o único tipo de arte não assimilado pela cultura de massa. A violência inconsciente da cultura de massa de impor uma facilitação forçada e regressiva da percepção estética reaparece na sua contraparte social, quer dizer, na música que se afasta do público leigo (: 107). Por isso mesmo, há o perigo de fazer da dificuldade um fetiche. Isso, contudo, não é razão para diminuí-la, o que mostra a complexidade de forças sociais com que o compositor atual se defronta na elaboração de uma linguagem formal. Basicamente, diria, é essa dificuldade inicial que, tornada prazer (ou gozo, nas palavras de Barthes) estético, fortalece o indivíduo contra as coerções e constrangimentos a que está sujeito em um sistema capitalista. Tal deleite estético fica evidente para quem cria gosto e apetite pelos novos universos musicais experimentados com as composições de Schönberg, Webern e, mais recentemente, Stockhausen, Xenakis, Dusapin e Kagel, entre outros.

Em Teoria estética, Adorno mostra que, embora a arte na modernidade tenha adquirido independência ideológica em relação a seus protetores, não teve mais a garantia de sua existência independentemente do mercado (: 110). $\mathrm{O}$ consumo da arte mais elaborada pode estar mais atrelado ao prestígio social que a uma assimilação legítima. Lembro que essa idéia foi muito repensada pelos teóricos da sociedade de consumo, em especial, pelo Baudrillard dos primeiros livros (Sociedade de consumo, Para uma crítica da economia política do signo). Nesse sentido, mesmo quando a obra não participa da falta de qualidade da mercadoria da indústria cultural, é percebida da mesma forma, e só é valorizada com os valores do mercado e do sistema de constrangimentos sociais que agem por trás da retórica da democracia e dos direitos iguais. Esse é o lado pernicioso da "desartificação" da arte, oposto à dessacralização que as vanguardas fazem da arte burguesa e que ganhou a simpatia das últimas reflexões de Adorno (: 113).

Depois de abordar os escritos sobre televisão e cinema, vem o capítulo V, que apresenta as reflexões do sociólogo Scott Lash sobre o que denomina "indústria cultural global" e de Ulrich Beck. Esse capítulo se diferencia bastante dos anteriores, mostrando que Rodrigo, ainda que seja um dedicado e incansável estudioso de Adorno e da teoria crítica, procura introduzir o leitor brasileiro no debate contemporâneo feito na Alemanha sobre a globalização. Rodrigo atenta para os otimismos e os aspectos críticos dos autores, comparando-os com a postura saudavelmente insatisfeita de Adorno em seu tempo. 
Em seguida, há uma pesquisa de quem são as grandes corporações atuais da indústria cultural e seus impérios quase monolíticos constituídos com base na falência de outras empresas, motivo da padronização generalizada das ofertas da cultura de massa. $\mathrm{O}$ autor também aponta as novas tendências na oferta de produtos culturais, principalmente na já existente, mas ainda prometedora, união da Internet com a televisão. Comparando o domínio da televisão até o início dos anos 1990 com a entrada da Internet, parece haver uma tendência para aumentar a capacidade de escolha do consumidor, o que tornaria o sistema de consumo mais democrático ou menos totalitário.

Em vez de sermos obrigados a ver uma série de propagandas, há uma tendência a pagar o serviço de transmissão e a oferta de produtos tanto na televisão ou na Internet quanto na fusão entre os dois. Embora haja aí uma forma de empresas lucrarem com a Internet do futuro, mostrando que ela nunca foi tão gratuita quanto se gostaria de acreditar, o crescente aumento da disponibilidade de produtos culturais oferecidos com tais serviços tende a aumentar e talvez estimular seu potencial democrático.

Permito-me agora, partindo desse livro tão instigante, uma reflexão sobre a atualidade. Não há dúvida de que há potencial emancipatório na Internet superior ao que havia na entrada do rádio e da televisão. A Internet não é somente mais um meio de comunicação, ela está mais próxima da enciclopédia ou da biblioteca que dos meios audiovisuais anteriores, permitindo uma interação singular entre as pessoas e as possibilidades de acesso e escolha das informações dificilmente equiparáveis em qualquer outra fase do capitalismo. Há uma grande resistência da intelectualidade a esse potencial menos por razões legítimas (ainda que elas existam) que pela falta de informação e até educação para o bom aproveitamento de suas capacidades atuais. Como uma biblioteca, a Internet tem tanto o pior quanto o melhor a oferecer, e cabe ao indivíduo desenvolver critérios de busca e seleção.

É difícil situar hoje a quantas anda o problema dos direitos autorais e até que nível a obra de arte alcançou no processo de desauratização. Nas experiências da cena da música eletrônica, por exemplo, não há mais controle de onde sai a matéria-prima do material sonoro: tudo é remixado de outras músicas, fragmentos são decompostos e recompostos, tudo é reciclagem, e depende sempre da força criativa do artista ser sucumbido pela mecanização dos procedimentos à disposição e pelas exigências do mercado, ou movido por uma busca singular. Apesar de ser exagerada, a posição adorniana da resistência da obra de arte à facilitação da recepção não é errônea, e a música erudita contemporânea continua mostrando, nes- 
se sentido, o quanto o público realmente foi deseducado a ter uma escuta atenta, pois não conseguiu até hoje assimilar a música atonal com a mesma desinquietação que o fez com a vanguarda das artes plásticas.

É difícil, portanto, situar onde estão os perigos e os elementos proveitosos da virtualidade e da informação tecnológica atuais, mas nem um otimismo nem um pessimismo irrefletidos podem nos guiar em um mundo que, em termos políticos e práticos, nos deixa em uma situação de completo desencanto, obrigados a não postular nenhum projeto de transformação absoluta; em termos tecnológicos, todavia, ele nunca ofereceu tanto e foi tão pouco refletido e mal aproveitado pela teoria. Rodrigo Duarte nos oferece de forma clara e consistente o pensamento de um daqueles que melhor elaborou essas questões em sua época, avançando de modo muito proveitoso no ensaio de seus desdobramentos contemporâneos.

Eduardo Guerreiro Brito Losso Doutorando em Ciência da Literatura [UFRJ] 